\title{
Evidence-based medicine in practice
}

Seeing patients in a busy teaching clinic presents various challenges. One challenge we frequently encounter is trying to practise evidence-based medicine in "real time," especially when trying to obtain and incorporate evidence in the few minutes we have with the residents. One method of tackling this problem is presented in the following scenario.

\section{Clinical scenario}

Our resident saw a 65 year old patient with congestive heart failure in the clinic. The patient brought in a news item from the internet stating that an "inexpensive drug cuts heart failure deaths by one third," and he wanted to know whether he could begin taking spironolactone as discussed in the news report. His medical history included a myocardial infarction. An echocardiogram done 6 months previously showed an ejection fraction of 35\%. He was breathless with New York Heart Association (NYHA) class III symptoms. His blood pressure was $130 / 70 \mathrm{~mm}$ $\mathrm{Hg}$, and his heart rate was 60 beats/minute. His medications were aspirin, $81 \mathrm{mg}$; atenolol, $50 \mathrm{mg}$; furosemide, $40 \mathrm{mg}$; and nitrospray as needed.

\section{Search and appraisal}

The resident recalled having heard a presenter at Noon Rounds advocate the use of spironolactone in patients with congestive heart failure and mentioned a recent trial published in the New England Journal of Medicine. The audience was surveyed at the end of Noon Rounds, and most said they would use spironolactone in their patients with congestive heart failure. While the resident was waiting for the patient to disrobe for the physical examination, he attempted to retrieve the article from the New England Journal of Medicine website to show us. By using the search terms "spironolactone" and "heart failure" and limiting the search to articles published from 1999 to 2001, he searched the contents of the New England Journal of Medicine. Within 32 seconds he retrieved 96 entries, and he was able to identify the relevant article as the first of these (figure 1$).{ }^{1}$ Within 2 minutes, he was able to download a PDF of the article and print it for review.

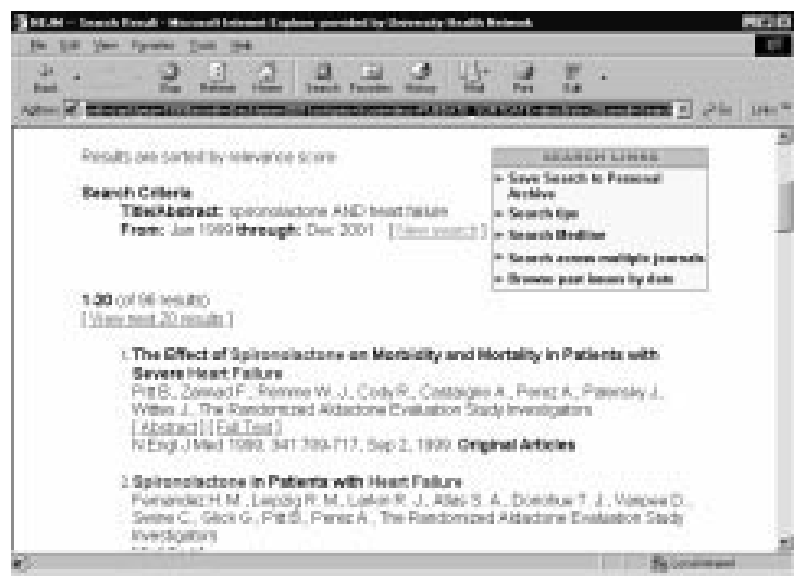

Figure 1 Search results on the New England Journal of Medicine website
While discussing the patient with us, the resident stated that based on his quick review of the abstract of this paper and the discussion during Noon Rounds, spironolactone would benefit the patient given that the study included patients with NYHA class III symptoms. The study was a randomised, placebo controlled trial of 1663 patients with severe heart failure. At 2 years of follow up, the mortality reduction was statistically significant between groups, with a relative risk reduction (RRR) of $25 \%$ and an absolute risk reduction of 11\% favouring spironolactone. Our resident believed these results were clinically significant as well. He proposed that a prescription for $25 \mathrm{mg}$ of spironolactone be given to the patient.

Another resident in the clinic was listening to the discussion while waiting to review her patient with us. She used the time to search ACP Journal Club online (www.acpjc.org) for a structured abstract and commentary of the pertinent spironolactone article (figure 2). By using the search terms "spironolactone" and "heart failure" she retrieved 3 citations within 20 seconds, and the first citation was the relevant article. By reviewing the informative abstract, she was able to determine that the study was high quality (a randomised controlled trial with an intention to treat analysis and follow up $\geqslant 80 \%$ ) and that spironolactone reduced all-cause mortality at 2 years (number needed to treat [NNT] 9, 95\% CI 6 to 15 ; RRR 25\%, 95\% CI 15 to $33 \%$ ) but increased the risk for gynaecomastia (number needed to harm 11). She was also quickly able to see from the abstract that patients included in the study were already using an angiotensin converting enzyme (ACE) inhibitor and a loop diuretic. She noted that the commentators asked whether patients would be best served by maximising the ACE inhibitor dose or by adding spironolactone, and she raised the issue that perhaps the initiation of an ACE inhibitor should be considered before spironolactone. The residents began a spirited discussion of the place of spironolactone in the management of patients with congestive heart failure.

We attempted to help the residents resolve the issue by searching Clinical Evidence to find a summary of the manage-

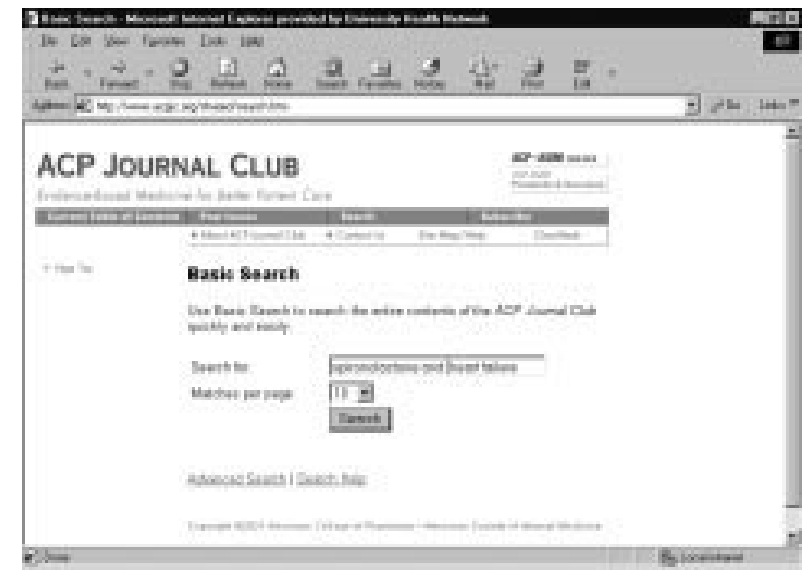

Figure 2 Search on the ACP Journal Club website 


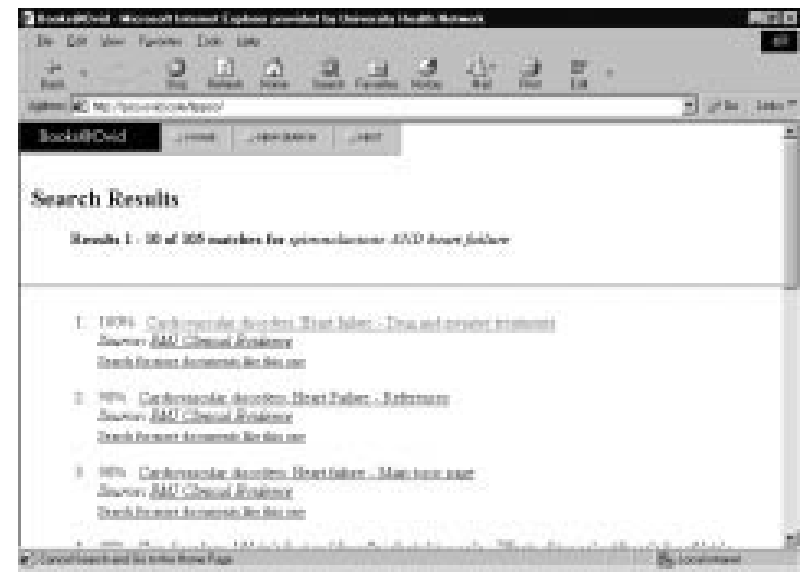

Figure 3 Search results in Clinical Evidence

ment of heart failure. By using the search terms "heart failure" and "spironolactone" we retrieved 105 relevant citations within 15 seconds, the first of which looked promising (Figure 3). The search yielded a discussion of the use of ACE inhibitors and other medications in patients with heart failure. From this summary, we saw that a systematic review comparing ACE inhibitors with placebo in patients with heart failure was identified and that it included $>7000$ patients. ${ }^{2}$ ACE inhibitors decreased the risk for death (NNT 16, CI 13 to 22; odds ratio 0.77, CI 0.67 to 0.88 ), and this benefit occurred in different subgroups of patients. A summary of the spironolactone study was also available in Clinical Evidence. We quickly saw that this study included 1663 patients, all taking ACE inhibitors and loop diuretics, with many taking digoxin as well. Clinical Evidence also included a discussion of other medical treatments (including both the risks and the benefits) for patients with congestive heart failure, and we were able to quickly review these with our residents.

\section{Applying the results}

Having presented the case and reviewed the evidence in less than 10 minutes, the resident who saw the patient decided not to proceed with spironolactone yet and instead to initiate ACE inhibitor treatment.

\section{Evaluating of the process}

We used an additional 2 minutes to discuss what was learned from the 3 searches used during this educational session. Although finding the relevant article in the New England Journal of Medicine did not take much time, sufficient time was not available in the clinic to read and appraise the article and to decide whether the evidence could be applied to the patient. By using ACP Journal Club online, our resident had access to the pre-appraised abstract and was quickly able to tease out the relevant issues. Finally, by using Clinical Evidence, the group was able to place the evidence into context with the other available evidence. We noted that although it is important for clinicians to keep up to date with and to use the current evidence, we must also be able to place it in context with the larger body of evidence that is known about the target disorder. We also illustrated that different medical reference databases have different uses and that it is important to match our need with what is available and with what time we have to search.

\section{SHARON E STRAUS, MD University of Toronto Toronto, Ontario, Canada}

1 Pitt B, Zannad F, Remme WJ, et al, for the Randomised Aldactone Evaluation Study Investigators. The effect of spironolactone on morbidity and mortality in patients with severe heart failure. N Engl J Med 1999;341:70917.

2 Garg R, Yusuf S, for the Collaborative Group on ACE Inhibitor Trials. Overview of randomized trials of angiotensin-converting enzyme inhibitors on mortality and morbidity in patients with heart failure. JAMA 1995;273:1450-6.

\section{Editors' note}

This note introduces a series we are launching in Evidence-Based Medicine titled the "Practice Corner," in which clinicians will describe methods they use for practising evidence-based medicine in the "real world." This series will alternate with editorials.

In clinical practice, we are not able to follow all 5 steps of practising evidence-based medicine ${ }^{3}$ for each clinical question that arises, and we develop shortcuts and other tools to allow us to act as users of evidence-based medicine. ${ }^{3}$ For example, in this "Practice Corner," use of different evidence resources has been highlighted, but the search strategies that were used were weak and unsophisticated. However, the strategies resulted in quick searches. We have learned a great deal from our colleagues who have developed various techniques for practising evidencebased medicine in different settings, and we have been able to share and modify our own methods of practising it based on these interactions. We hope that this new section of EvidenceBased Medicine can facilitate such learning for all clinicians interested in practising evidence-based medicine.

We invite you to submit ideas for tools and methods you have found that make practising evidence-based medicine a success in your own clinical settings. Please send your suggestions to sstraus@mtsinai.on.ca. We look forward to sharing these with all our readers.

THE EDITORS

1 Straus SE, McAlister FA. Evidence-based medicine: a commentary on common criticisms. CMAJ 2000;163:837-41. 